\title{
Exogenous Factors
}

National Cancer Institute

\section{Source}

National Cancer Institute. Exogenous Factors. NCI Thesaurus. Code C19688.

Environmental factors considered as variables in disease incident, transmission, and control. 